\title{
The senior anesthesiologists and their medical profession in Korea: based on a survey
}

\section{Kyungmi Kim ${ }^{1}$, Sungwoon Baek ${ }^{1}$, In-Cheol Choi', and Hong-Seuk Yang ${ }^{2}$}

Department of Anesthesiology and Pain Medicine, ${ }^{1}$ Asan Medical Center, College of Medicine, University of Ulsan, Seoul, ${ }^{2}$ Daejeon Eulji Medical Center, Medical College, Eulji University, Daejeon, Korea

Received September 1, 2020

Revised December 29, 2020

Accepted January 5, 2021

\begin{abstract}
Background: The number of aging physicians is increasing as the global population ages. With aging, anesthesiologists would be expected to experience changes in their professional position. Therefore, we aimed to investigate the current professional status of Korean anesthesiologists aged over 60 years.
\end{abstract}

Methods: Registered anesthesiologists aged over 60 years in Korea were invited for a survey. The questionnaire addressed 10 subjects with 40 questions that focused on demographics, practical activities, work conditions, difficulties experienced due to physical changes caused by aging, and economic status.

Results: In total, 122 anesthesiologists responded to the survey (response rate: $15.7 \%$ ). Of them, 30.3\% were working in honorary and advisory positions at tertiary hospitals, while $19.7 \%$ were working as pain physicians. Majority of the respondents were working for 5 days a week (41.8\%) and $6-8$ hours/day (48.4\%). Majority of them (79.5\%) were generally satisfied with their present life.

Conclusions: Majority of the senior anesthesiologists were working at general hospitals and they reported being "satisfied" with the current status of their life. However, the clinical practice and retirement strategies of senior anesthesiologists need to be evaluated systematically to prepare for the continuing gradual increase in the number of senior anesthesiologists.

Keywords: Aging; Anesthesiologists; Republic of Korea; Surveys and questionnaires.

\section{INTRODUCTION}

Aging is a fact of nature and it is an irreversible process. Similar to the general population, anesthesiologists are aging [1]. Aging does not necessarily imply the presence of any abnormalities in mental or physical status. It could, however, sometimes cause problems for senior anesthesiologists while performing their occupational activities. Aging gradually decreases physical and cognitive function. It also prolongs the response time during physical and cognitive activities [2]. These physiological and cognitive functional changes in senior anesthesiologists may cause them to feel fatigued easily, and they may consider changing their professional activities or position [3].

Anesthesia is a demanding field and it requires highly concentrated vigilance on the vital signs of patients, the application of skillful techniques, and sufficient physical fitness to engage in anesthetic practice. In addition, it re-

This is an Open Access article distributed under the terms of the Creative Commons Attribution Non-Commercial License (http://creativecommons.org/licenses/by-nc/4.0) which permits unrestricted non-commercial use, distribution, and reproduction in any medium, provided the original work is properly cited.

Copyright (C) the Korean Society of Anesthesiologists, 2021 
quires the ability to make prompt decisions to deal with unexpected changes in the patient's condition [1]. Several reports have mentioned that aged practitioners, including anesthesiologists, are more likely to experience legal issues related to their practice $[1,4,5]$. In contrast, some studies have reported that aged surgeons did not experience increased rates of adverse events in their patients [6-8]. Nevertheless, numerous societies of physicians, as well as anesthesiologists, have started preparing for their aging, and providing a preparative program for retirement $[5,9,10]$.

The Korean Society of Anesthesiologists has also started considering the issue of aging. There are individual variabilities in age-related physiological changes. Generally, anesthesiologists in Korea would expect to experience changes in their professional position after their 60 s, such as stepping back from working full-time, moving to another institution, working outside the operating room, starting their own practice, or simply retiring. The Korean Society of Anesthesiologists, however, does not have confirmative data about the professional status of senior anesthesiologists. Therefore, it is necessary to study senior Korean anesthesiologists' professional status and conditions to help them plan for their retirement. Accordingly, we surveyed the current professional status and quality of life of Korean anesthesiologists older than 60 years using a postal mail and an emailed Google survey.

\section{MATERIALS AND METHODS}

The Korean Society of Anesthesiologists has a registry system to manage the licenses of anesthesiologists, which is controlled by the government. After receiving approval from the Korean Society of Anesthesiologists, we checked the registry and confirmed that 5,269 anesthesiologists were currently practicing in Korea. Among them, 844 anesthesiologists were older than 60 years (based on their birthday, i.e., those born before December 31, 1959). We validated that 776 of these anesthesiologists were living in Korea during 2018. Subsequently, we sent a postal questionnaire to them and received their responses from March 1, 2019 to April 30, 2019. Then, between July 1, 2019 and August 31, 2019, we sent an email questionnaire to non-respondents, in case we had their incorrect postal address.

The questionnaire addressed 10 subjects with 40 questions that focused on demographics, satisfaction with their life, practical activities, scale of the workplace, work conditions, difficulties caused by physical changes related to ag- ing, economic status, and retirement plans. All respondents answered each question based on their own judgment. Depending on the type of the question, respondents either ranked the response in the order of " 1,2 , and 3 ," or they chose the most preferred example (Supplementary Data 1). Responses were collected and analyzed using the Google survey program (Supplementary Data 2). A univariate logistic regression analysis was performed to identify the factors affecting the respondents' satisfaction with their life, including age, sex, scale of the workplace, having duties, experiencing physical difficulty, salary, and satisfaction with their income. Variables with a $\mathrm{P}$ value $<0.05$ in the univariate analysis were included in the multivariate logistic regression analysis to determine the impact of the independent factors on the respondents' satisfaction with their life. A P value $<0.05$ was considered statistically significant. A linear regression with the Durbin-Watson test was performed to determine the absence of autocorrelation in the final multivariate logistic regression model. Linear and logistic regression analyses were performed using IBM SPSS Statistics 21.0 software (IBM Co., USA).

\section{RESULTS}

We received 105 responses from postal mails and 17 email responses. The total response rate was $15.7 \%$. Respondents were primarily male (83.6\%). Fig. 1 shows the age distribution of the survey respondents. Majority of the respondents $(\mathrm{n}=88)$ were in their 60 s and 4 were older than 80 years. Table 1 shows the location of their residence and workplace. Most respondents' residence and workplace were concentrated in the Seoul metropolitan area, which included Seoul $(49,40.2 \%)$ and Gyeonggi-do Province $(17,13.9 \%)$. Most respondents continued to work as practitioners (113 respondents) at the time of the survey,

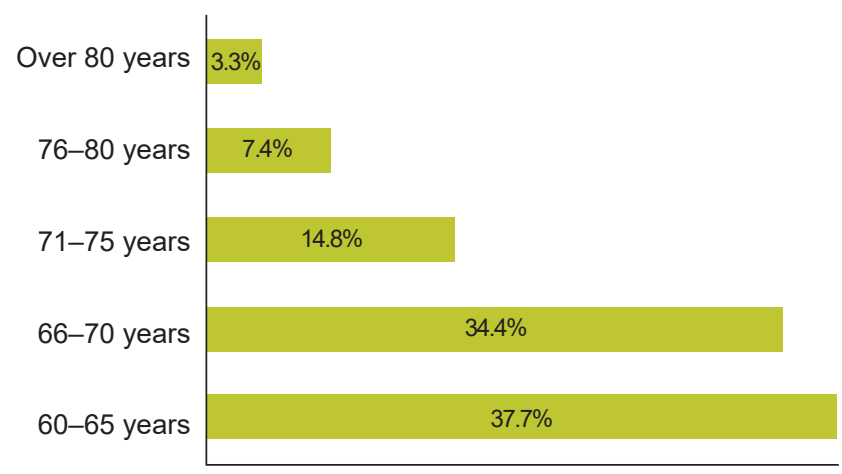

Fig. 1. Age distribution of survey respondents. Majority $(n=88)$ were in their 60s. 
Table 1. Respondents' Work and Residence Locations

\begin{tabular}{|c|c|c|c|c|}
\hline \multirow{2}{*}{ Location } & \multicolumn{2}{|l|}{ Residence } & \multicolumn{2}{|l|}{ Work } \\
\hline & Number of respondents (persons) & Rate (\%) & Number of respondents (persons) & Rate (\%) \\
\hline Seoul & 49 & 40.2 & 38 & 30.9 \\
\hline Busan & 9 & 7.4 & 9 & 7.3 \\
\hline Daegu & 5 & 4.1 & 4 & 3.3 \\
\hline Incheon & 5 & 4.1 & 7 & 5.7 \\
\hline Gwangju & 11 & 9 & 7 & 5.7 \\
\hline Daejeon & 6 & 5 & 8 & 6.5 \\
\hline Ulsan & 1 & 0.8 & 1 & 0.8 \\
\hline Gyeonggi-do & 17 & 13.9 & 24 & 19.5 \\
\hline Gangwon-do & 1 & 0.8 & 1 & 0.8 \\
\hline Chungcheongnam-do & 1 & 0.8 & 1 & 0.8 \\
\hline Chungcheongbuk-do & 1 & 0.8 & 2 & 1.6 \\
\hline Jeollabuk-do & 6 & 4.9 & 7 & 5.7 \\
\hline Jeollanam-do & 1 & 0.8 & 2 & 1.6 \\
\hline Gyeongsangbuk-do & 1 & 0.8 & 3 & 2.4 \\
\hline Gyeongsangnam-do & 6 & 4.9 & 6 & 4.9 \\
\hline Jeju-do & 1 & 0.8 & 1 & 0.8 \\
\hline Overseas & 1 & 0.8 & 1 & 0.8 \\
\hline
\end{tabular}

while 9 respondents had retired. Almost all of the respondents had been working for more than 15 years at the same workplace.

Thirty percent of the respondents worked at tertiary referral hospitals, another $30 \%$ worked at secondary hospitals, and $20 \%$ had their own primary clinic (Fig. 2A). Fig. 2B shows that majority of the respondents worked only during the day, while some had night duty (16.4\%) or on-call duty (18.9\%). Majority of the respondents worked for 6-8 hours/ day $(51.6 \%)$, while $34.4 \%$ worked for more than $8 \mathrm{~h}$ a day (Fig. 2C). Majority of the respondents (41.8\%) worked for 5 days per week, while $30 \%$ of them worked for more than 6 days per week (Fig. 2D). Fig. 3 presents the age distribution of respondents who had night duty or on-call duty depending on the scale of their workplace. Majority of the respondents who had night duty or on-call duty were in their 60 s. Further, those in their early 60s who had night duty or oncall duty worked at tertiary or secondary hospitals. As compared to the other types of workplaces, nursing hospitals had a higher proportion of older respondents.

The primary role of the respondents in their workplace was that of an anesthesiologist (47.8\%), pain physician (19.5\%), both of these $(14.2 \%)$, or a general physician (12.4\%). The majority of respondents had 5-10 cases of anesthesia $(20.5 \%)$ per day and $20-50$ patients being treated at a pain clinic (18.9\%). The respondents reported the following reasons why they had different roles to anesthesiologists or pain physician at their workplace: enjoying lei- surely time (31.8\%), income (27.3\%), and eager to learn about other fields (22.7\%). The main source of income for the respondents was their earned income as a physician $(77.9 \%)$. Only $14 \%$ of the respondents earned their living from pensions. Approximately $70 \%$ of the respondents were satisfied with their income derived from their work.

Thirty-one percent of the respondents reported difficulties in performing their clinical practice duties due to physical changes caused by aging (Table 2). The most stressful aspect of their practice was night and weekend duties (21.3\%). Other common difficulties included decreased fine motor movement (9.0\%) and presbyopia (18.9\%). The mean age of retirement among the retired respondents was 72 years. Majority of the respondents hoped to work into their 70 s (44.2\%).

Majority of the respondents $(97,79.5 \%)$ answered that they were generally satisfied with their present life (Fig. 4). The univariate logistic regression analysis revealed that age, sex, scale of the workplace, and salary were not associated with the respondents' satisfaction with their life (Table 3 ). However, experiencing physical difficulty and satisfaction with income were associated with satisfaction with life. Specifically, those who experienced physical difficulties were 0.4 times less likely to be satisfied with their life than were those who did not. Further, those who were satisfied with their income were 11.8 time more likely to be satisfied their life than their counterparts. The multivariate logistic regression analysis indicated that satisfaction with income 

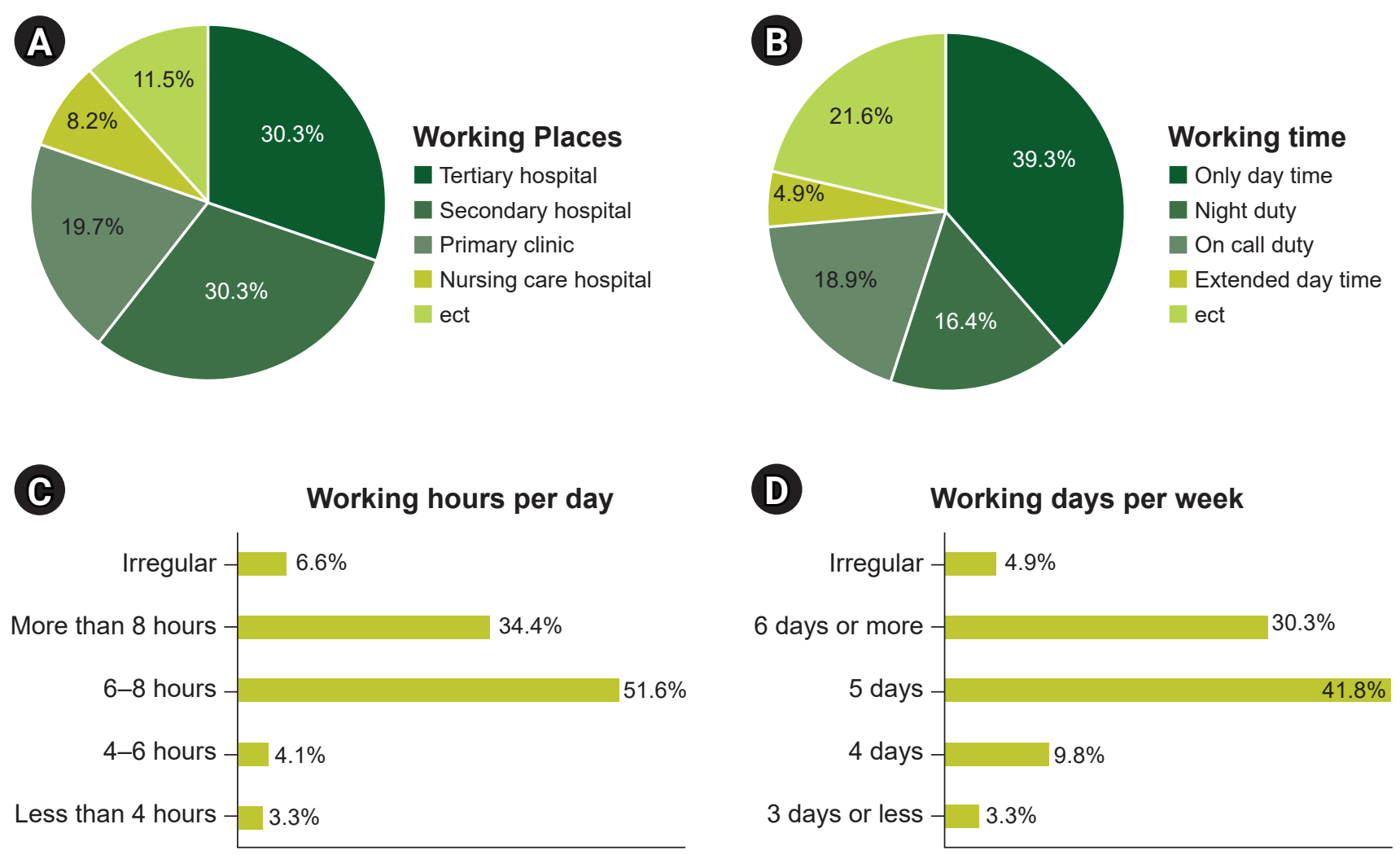

Fig. 2. Working conditions of the respondents. (A) Workplace. Thirty percent of the respondents worked at tertiary referral hospitals, another $30 \%$ worked at secondary hospitals, and $20 \%$ worked at their own primary clinic. (B) Working time. Majority of the respondents worked only during the day. Some reported having night duty (16.4\%) or on-call duty (18.9\%). (C) Working hours. Majority of the respondents worked for $6-8$ hours/day (51.6\%), followed by $34.4 \%$ who worked for more than $8 \mathrm{~h}$ a day. (D) Working days. Majority of the respondents worked for 5 days per week (41.8\%), followed by $30.3 \%$ who worked for more than 6 days per week.

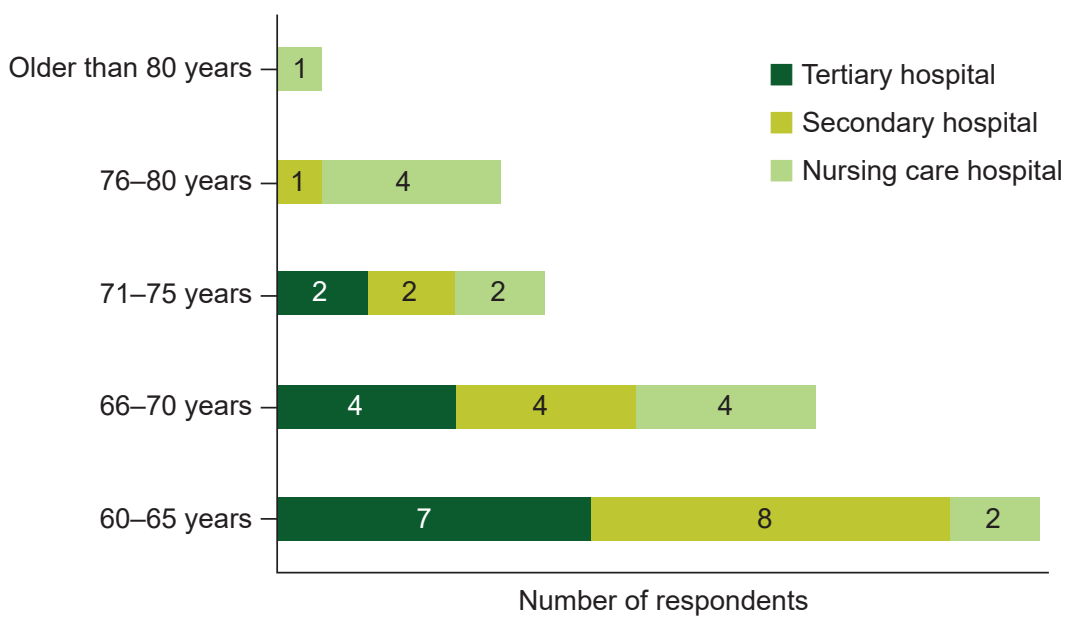

Fig. 3. Age distribution of respondents who had night duty or on-call duty depending on the scale of the workplace. Majority of the respondents who had night duty or on-call duty were in their 60s. Those in their early 60 s who had night duty or on-call duty worked at tertiary or secondary hospitals. As compared to other types of workplaces, nursing hospitals had a higher proportion of older respondents.

was an independent factor that was significantly associated with satisfaction with life (Table 3 , Adjusted $\mathrm{R}^{2}=0.242$, Durbin-Watson $=1.875)$.

\section{DISCUSSION}

Our data revealed the current professional status of senior anesthesiologists in Korea. A total of 122 anesthesiolo- 
gists older than 60 years answered our questionnaire (response rate: $15.7 \%$ ). Although some of the respondents felt

Table 2. Difficulties Pertaining to Physical Activity During Clinical Practice $(n=35$, multiple responses were allowed)

\begin{tabular}{lcc}
\hline \multicolumn{1}{c}{ Difficulties due to aging } & $\begin{array}{c}\text { Number of respondents } \\
\text { (persons) }\end{array}$ & Rate (\%) \\
\hline Night duty & 15 & 42.9 \\
Weekend duty & 8 & 22.9 \\
Presbyopia & 13 & 37.1 \\
$\begin{array}{l}\text { Decreased fine motor } \\
\text { movement }\end{array}$ & 5 & 14.3 \\
\hline
\end{tabular}

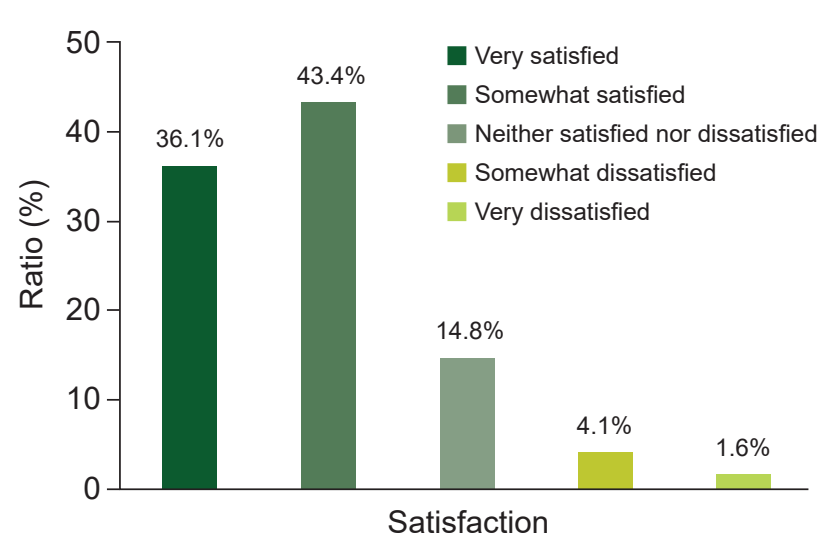

Fig. 4. Respondents' satisfaction with life. Majority of the respondents (97, $79.5 \%)$ answered that they were generally satisfied with their present life. that they were aging and they experienced discomfort from the related physical changes, most of them (92.6\% of respondents) continued with their occupation. The common physical difficulties reported were decline in physical strength, presbyopia, and decreased fine motor movement. Majority of the respondents $(79.5 \%)$ were generally satisfied with their present life.

The age distribution of physicians has changed substantially over the past three decades [1]. In 2010 in the United States and in 2012 in Canada, 39.5\% and $41.7 \%$ of physicians, respectively, were aged over 55 years [3]. In France, $52.5 \%$ of the anesthesiologists were older than 50 years in 2005 [1]. However, especially in the field of anesthesiology, it is impossible to keep producing young physicians to meet the demand. Schubert et al. [11] reported that the trend of an estimated shortage of anesthesiologists would only grow in the next decade, with an expected shortage of 12,500 anesthesiologists by 2020 . According to the research and development (RAND) corporation study, a shortage of anesthesiologists has existed since 2017 due to the combined effects of retirement and graduation rates. The gradual decline in the number of practicing anesthesiologists will persist at least for the next decade [12]. Anesthesiologists are highly trained specialists who are responsible for ensuring patients' safety during the perioperative period.

Table 3. Logistic Regression Analysis on Factors Independently Related to Life Satisfaction

\begin{tabular}{|c|c|c|c|c|}
\hline \multirow{2}{*}{ Variable } & \multicolumn{2}{|c|}{ Univariate analysis } & \multicolumn{2}{|c|}{ Multivariate analysis } \\
\hline & Odds ratio $(95 \% \mathrm{Cl})$ & $P$ value & Odds ratio $(95 \% \mathrm{Cl})$ & $P$ value \\
\hline Age group & & 0.304 & & \\
\hline Sixties & 1 & & & \\
\hline Seventies & $0.632(0.195-2.049)$ & & & \\
\hline Older than seventies & $3.632(0.480-27.504)$ & & & \\
\hline Sex, male & $2.383(0.783-7.249)$ & 0.126 & & \\
\hline Scale of the workplace & & 0.071 & & \\
\hline Primary clinic & 1 & & & \\
\hline Secondary hospital & $2.593(0.633-10.626)$ & & & \\
\hline Tertiary hospital & $0.618(0.114-3.348)$ & & & \\
\hline Nursing care hospital & $4.667(0.811-26.866)$ & & & \\
\hline Others & $3.889(0.762-19.858)$ & & & \\
\hline Having duties & $0.627(0.256-1.535)$ & 0.306 & & \\
\hline Experiencing physical difficulty & $0.400(0.163-0.984)$ & 0.046 & $0.369(0.129-1.058)$ & 0.063 \\
\hline Salary (KRW) & & 0.739 & & \\
\hline$\sim 5,000,000$ & 1 & & & \\
\hline$\sim 7,500,000$ & $0.450(0.081-2.488)$ & & & \\
\hline$\sim 10,000,000$ & $0.682(0.173-2.694)$ & & & \\
\hline$>10,000,000$ & $0.500(0.123-2.038)$ & & & \\
\hline Satisfaction with income & $11.839(4.220-33.214)$ & $<0.001$ & $11.342(3.951-32.559)$ & $<0.001$ \\
\hline
\end{tabular}

Cl: confidence interval, KRW: Korean won. Adjusted $R^{2}=0.242$, Durbin-Watson $=1.875$. 
As medical practitioners, they have to develop medical knowledge, hold appropriate qualifications to apply this information to clinical practice, and be responsible for maintaining adequate anesthesia while ensuring patient safety [13]. Moreover, anesthesiologists are required to fulfill leadership roles by organizing surgeons, nurses, and paramedics in an operating room. Thus, anesthesiologists are required to provide total perioperative care services to their patients and to cooperate with all members of the operating room staff.

Indeed, anesthesiologists' role is highly stressful. Such stressful and complex tasks are associated with exhausted physicians. Thus anesthesiologists are prone to be fatigued due to the need to maintain constant vigilance during working hours [14]. Aging generally decreases physical abilities and cognitive function, and causes fatigue. Patients' safety is not guaranteed when they are placed under the care of an aged, fatigued anesthesiologist whose cognitive, sensory, and motor responses are impaired [15]. Therefore, aging is the most sensitive factor among anesthesiologists who intend to maintain their profession.

Several American societies of physicians are starting to prepare for their aging and longevity. For instance, the American College of Surgeons recommended surgeons to undergo voluntary physical examination and visual testing at regular intervals from the age of 65 to 70 years [6]. The American Academy of Orthopaedic Surgeons emphasized the importance of timely identification of decreased clinical and cognitive skills of physicians. Accordingly, they suggested that assessment tools and measures need to be developed to detect these impairments [16]. To ensure patient safety and the occupational health of anesthesiologists, several societies of anesthesiologists have also recommended a "winding down practice" guideline, although the aging process is diverse and depends on the individual. For instance, a Canadian anesthesiologists' society suggested that physicians refrain from accepting "overnight on-call" duties from the age of 60 years and they avoid intense cases after the age of 65 years. Instead, it recommends that they transfer to mentoring or non-operating room activities [3]. Moreover, they suggested the use of a simulation program annually by anesthesiologists after the age of 60 years to evaluate their abilities to cope with a crisis in the operating room. The Australian and New Zealand College of Anaesthetists recommended that every anesthesiologist should receive advice from a general practitioner on their health [10]. Furthermore, the Association of An- aesthetists of Great Britain and Ireland suggested that anesthesiologists aged over 55 years should require clinical directors to review their on-call responsibilities [17].

Our data were consistent with the findings of a previous study $[18,19]$, where numerous senior physicians thought that their physical limitations were the main problem impairing the longevity of their professional life. During aging, muscle mass decreases along with muscle strength. Therefore, senior anesthesiologists are vulnerable to long working hours and night duties. Orkin et al. [20] reported that the most important factors for the retirement of anesthesiologists were requirements for night calls and extended work hours. Presbyopia and age-related visual impairments, such as cataracts and glaucoma, were also mentioned as difficulties that prevented senior anesthesiologists from continuing to work.

Most of the respondents in our study answered that their main source of income was earned from their work as a physician. Therefore, senior anesthesiologists intended to continue to work. Aging anesthesiologists developed their own financial solutions to fund their retirement. A few societies of anesthesiologists have recommended establishing a fund or a pension to prepare for financial problems after retirement [1].

This study had some limitations. It is just a survey, not a task force report. Results obtained through a survey have natural biases since all responses are self-reported by the respondents, and they may not be completely true. Besides, it is possible that only those respondents who were already satisfied with their life tended to respond to the survey. This limitation could have affected the results of the survey. Although this study had a 15\% response rate, some reports have advised that high response rates are not necessary for a valid survey $[21,22]$. Moreover, we only checked the current professional status of senior anesthesiologists in Korea; therefore, we could not suggest any guidelines or recommendations.

While a few societies of anesthesiologists have suggested the use of simulation education programs to provide practitioners an opportunity to refresh their knowledge and adapt to new information, and to check the psychophysical capabilities of senior anesthesiologists, it is important to acknowledge that aging leads to not only the decline of psychophysical capacities but also the expansion of experience and wisdom $[1,3,5]$. Senior physicians could help juniors or trainees by sharing their knowledge and wisdom based on their own experiences. A communication pro- 
gram between junior and senior anesthesiologists would help both groups build on their strengths. In addition, sur results have revealed the need for developing a programmed scheme to prepare for career longevity as have other anesthesiologists' societies. There is a need to prepare physicians for aging, and to continue simulation education to encourage the clinical and practical activity of senior anesthesiologists. A systematic evaluation of a clinical practice strategy for senior anesthesiologists is needed to prepare for the gradually increasing numbers of senior anesthesiologists in Korea.

In conclusion, although several respondents felt that they were aging and they experienced discomfort from the related physical changes, majority of them were satisfied with their current life. It is necessary to provide clinical practice strategies to support senior anesthesiologists and to help them prepare for career longevity.

\section{SUPPLEMENTARY MATERIALS}

Supplementary data including a survey can be found online at https://doi.org/10.17085/apm.20071.

\section{CONFLICTS OF INTEREST}

No potential conflict of interest relevant to this article was reported.

\section{DATA AVAILABILITY STATEMENT}

All data generated or analyzed during this study are included in this published article.

\section{AUTHOR CONTRIBUTIONS}

Conceptualization: In-Cheol Choi, Hong-Seuk Yang. Data curation: Kyungmi Kim, Sungwoon Baek, Hong-Seuk Yang. Formal analysis: Kyungmi Kim, Sungwoon Baek. Methodology: Kyungmi Kim, Hong-Seuk Yang. Project administration: In-Cheol Choi, Hong-Seuk Yang. Visualization: Kyungmi Kim, Sungwoon Baek. Investigation: In-Cheol Choi, HongSeuk Yang. Software: Kyungmi Kim, Sungwoon Baek. Supervision: In-Cheol Choi, Hong-Seuk Yang. Validation: In-Cheol Choi. Writing -original draft: Kyungmi Kim. Writing - review \& editing: Kyungmi Kim, Hong-Seuk Yang.

\section{ORCID}

Kyungmi Kim, https://orcid.org/0000-0003-2833-1912

Sungwoon Baek, https://orcid.org/0000-0002-7445-1352

In-Cheol Choi, https://orcid.org/0000-0002-5344-9085

Hong-Seuk Yang, https://orcid.org/0000-0003-2023-8705

\section{REFERENCES}

1. Giacalone M, Zaouter C, Mion S, Hemmerling TM. Impact of age on anaesthesiologists' competence: a narrative review. Eur J Anaesthesiol 2016; 33: 787-93.

2. Mani TM, Bedwell JS, Miller LS. Age-related decrements in performance on a brief continuous performance test. Arch Clin Neuropsychol 2005; 20: 575-86.

3. Baxter AD, Boet S, Reid D, Skidmore G. The aging anesthesiologist: a narrative review and suggested strategies. Can J Anaesth 2014; 61: 865-75.

4. Tessler MJ, Shrier I, Steele RJ. Association between anesthesiologist age and litigation. Anesthesiology 2012; 116: 574-9.

5. Katz JD. The aging anesthesiologist. Curr Opin Anaesthesiol 2016; 29: 206-11.

6. Dellinger EP, Pellegrini CA, Gallagher TH. The aging physician and the medical profession: a review. JAMA Surg 2017; 152: 967-71.

7. Risucci D, Geiss A, Gellman L, Pinard B, Rosser J. Surgeon-specific factors in the acquisition of laparoscopic surgical skills. Am J Surg 2001; 181: 289-93.

8. Prystowsky JB. Are young surgeons competent to perform alimentary tract surgery? Arch Surg 2005; 140: 495-500; discussion 500-2.

9. Baxter A, Thompson C, McCartney C. "Winding down" guidelines for anesthesiologists: the Ottawa Hospital plan. Can J Anaesth 2016; 63: 1204-6.

10. Baker AB. The ageing practitioner: ANZCA's recommendations. Australas Psychiatry 2016; 24: 151-4.

11. Schubert A, Eckhout GV, Ngo AL, Tremper KK, Peterson MD. Status of the anesthesia workforce in 2011: evolution during the last decade and future outlook. Anesth Analg 2012; 115 : 407-27.

12. Tremper KK. Anesthesiology staffing shortages - winter is coming. Decision Support Whitepaper Series [Internet]. 2019 Nov [2020 Nov 17]. Available from https://www.alertwatch.com/ anesthesia-staffing-shortage-winter-is-coming/.

13. Bajwa SJ, Kaur J. Risk and safety concerns in anesthesiology practice: the present perspective. Anesth Essays Res 2012; 6: 
$14-20$.

14. Gurman GM, Klein M, Weksler N. Professional stress in anesthesiology: a review. J Clin Monit Comput 2012; 26: 329-35.

15. Sinha A, Singh A, Tewari A. The fatigued anesthesiologist: a threat to patient safety? J Anaesthesiol Clin Pharmacol 2013; 29: 151-9.

16. Hickson GB, Peabody T, Hopkinson WJ, Reiter CE 3rd. Cognitive skills assessment for the aging orthopaedic surgeon: AOA critical issues. J Bone Joint Surg Am 2019; 101: e7.

17. The Association of Anaesthetists of Great Britain and Ireland (AAGBI). Working arrangements for consultant anaesthetists in the United Kingdom. London, AAGBI. 2011.

18. Howard SK, Rosekind MR, Katz JD, Berry AJ. Fatigue in anesthesia: implications and strategies for patient and provider safety. Anesthesiology 2002; 97: 1281-94.

19. Katz JD. Issues of concern for the aging anesthesiologist. Anesth Analg 2001; 92: 1487-92.

20. Orkin FK, McGinnis SL, Forte GJ, Peterson MD, Schubert A, Katz JD, et al. United States anesthesiologists over 50: retirement decision making and workforce implications. Anesthesiology 2012; 117: 953-63.

21. Sobal J, Ferentz KS. Comparing physicians' responses to the first and second mailings of a questionnaire. Eval Health Prof 1989; 12: 329-39.

22. Hikmet N, Chen SK. An investigation into low mail survey response rates of information technology users in health care organizations. Int J Med Inform 2003; 72: 29-34. 